\title{
Stone Age Man in Kenya Colony.
}

\author{
By X. S. B. Leaky.
}

$\mathrm{I}^{\mathrm{s}}$ S September 1926 I sailed from Englayd accompanied by Mr. B. H. Newsam to investigate certain prehistoric sites which I bad known of for some years in Kenya Colony. My expedition received financial aid from the Percy Sladen Memorial Fund and the Government Grant Committee of the Royal Society, the assistance of which is gratefully acknowledged. Stone tools of many types had been collected by myself and many others from the surface in Kenya Colony and the other East African territories for a good many years, and it was hoped that the work of the expedition this year would bring to light sites containing stone tools associated with human remains.

This expectation has been more than justified, as the following details will show, and it is hoped that the finds which have been made will prove sufficiently important to call forth more extensive financial assistance, so that work may be continued in 1928 on a more com. prehensive scale. A large number of further sites of great promise have been located. Until the specimens obtained have been brought to England and submitted to experts and carefully examined and compared with. other prehistoric remains, it is naturally undesirable that I should make any definite statement as to the racial or cultural affinities of my finds, so the following general statement and outline must for the present suffice.

\section{The Nakuru Site.}

The first site excavated which yielded important results was situated on Major Macdonald's farm, Nakuru. Traces of ten burials were found in the lower levels of the deposit at depths ranging from $8 \mathrm{ft}$. to $12 \mathrm{ft}$. The majority of these human remains were very fragmentary with the exception of Skull No. 3 and Skeleton No. 9, which was in an almost perfect state of preservation. This find was reported in the Times of Dec. 28 last. All the human remains found were definitely associated with a microlithic industry which I consider Mesolithic, and which bears striking resemblances to that industry in Uganda which Mr. Wayland has named Magosian. No attempt has been made to classify the tools out here, but this will be done immediately on arrival in England.

The skulls from the Nakuru site (see Fig. 1) do not resemble the skulls of the modern negro races inhabiting this country; nor, apart from extreme dolichocephaly, do they show any of the more marked characters usually considered typical of existing negro or negroid races. The face, instead of being short, is very long, but is not disharmonic as it is proportionately broad, giving an upper facial index of $57 \cdot 1$. The nasal opening is only of medium width, the nasal index being 50.9. The nasal bones are long and are not flattened as in typical negroes, and there is a medium bridge. The lower margin of the nasal aperture has a well-defined sill and not the groove so common in negroid skulls.

The mandible is remarkable in several respects. The horizontal ramus is very deep, especially in the region of the chin, which is very pronounced. The ascending ramus is also very high. This is largely due to, and necessitated by, the great height of the vault of the palate, which-measured from the chewing surface of the second molars-is $29 \mathrm{~mm}$. This is remarkable, being as great a height as that recorded for Rhodesian man by Sir Arthur Keith ("The Antiquity of Man," vol. 2, p. 400). This

$$
\text { No. } 3011 \text {, VoL. 120] }
$$


In the deposit with the human remains were found a number of obsidian tools mainly of a more primitive type than those from Nakuru, but including a few lunates and other Nakuru types. There was also a certain amount of pottery, some of it with the same decoration as found on the Nakuru examples; numerous animal bones, including skulls, mandibles, and teeth; disc shell beads; and one stone bowl similar to one of the Nakuru types.

At first it was thought that the skulls from the two sites were of the same type, but this is not substantiated by a close comparison made recently, although there are certain similarities. It is even doubtful if all the skulls from the Elmenteita site will prove to belong to the same race. Nevertheless, all the mandibles from this site show common characters, while they differ markedly from the Nakuru mandible.

Skull A from Elmenteita is certainly different from Skull No. 9 from Nakuru. The photographs

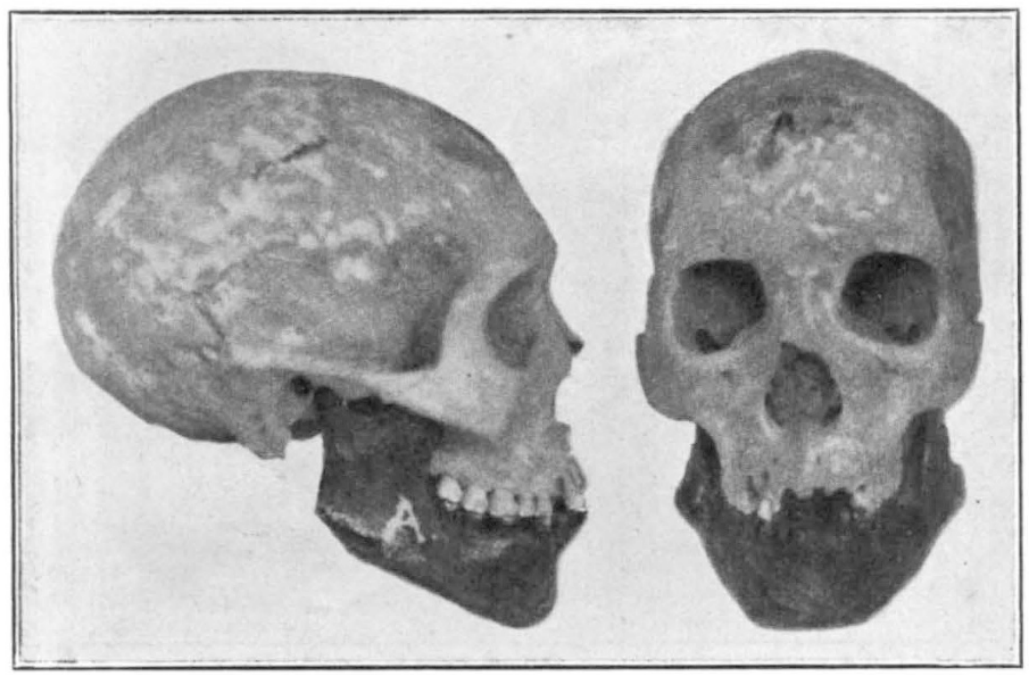

Fig. 2.- Side and front views of Skull $A$ from the Elmenteita site. graph. The similarities lie in the length of the skull as compared to the breadth, the cranial indices boing 68.2 (Elmt.) and 69.8 (Nak.) ; the upper facial length, which is $80 \mathrm{~mm}$. in both specimens; and the bi-zygomatic breadth, which in each case is greater than the maximum skull breadth, being $136 \mathrm{~mm}$. (Elmt.) and $140 \mathrm{~mm}$. (Nak.).

Another skull type found at Elmenteita has a much broader skull, giving a cranial index of 76 . It has a good forehead, and is orthognathous. This type, however, also differs from the Nakuru type.

Perhaps the most surprising feature of the Elmenteita crania is the narrowness of the nose as compared with the length. The four specimens upon which it is possible to take measurements yield the following results :

\begin{tabular}{|c|c|c|c|c|}
\hline & & Length. & Breadth. & $\begin{array}{c}\text { Index. } \\
47.4\end{array}$ \\
\hline Skull ' $\mathrm{B}$ ', & & $60 \mathrm{~mm}$. & $24 \mathrm{~mm}$. & 40 \\
\hline Skull ' $\mathrm{C}$ ' & . & $50 \mathrm{~mm}$. & $22 \mathrm{~mm}$. & 44 \\
\hline Skull 'D' & . & $50 \mathrm{~mm}$. & $22 \mathrm{~mm}$. & 44 \\
\hline
\end{tabular}

These figures are certainly not those suggestive of negro affinities. It scems doubtful even if those Negroid races which to-day have narrow noses can approximate to these figures.

Full details of the work done and objects found will be published as soon as possible after our return to England in September with this season's specimens.

In Nature for Jan. 8, p. 61, there is a short note on my work based on a report in the Times of Dec. 28, 1926. This note contained some inaccuracies and $\mathrm{I}$ would be grateful if I may be permitted to correct two of them. I am referred to as " of the Cutler Dinosaur Expedition." I am not a member of this expedition, nor, so far as I know, has (reproduced as Figs. 1 and 2) show both the similarities and the differences. In the Elmenteita skull the forehead is low and receding; the nose is much longer than in the Nakuru skull, while the width is much the same, this resulting in a lower index, which is actually $47 \cdot 4$. Moreover, instead of a sill at the base of the nose there is a groove; there is a trace of sub-nasal prognathism, the alveolar index being 103 ; the height of the vault is nothing like so great, while the mandible is of a quite different type. This is amply brought out in the photo- an expedition under such name cxisted out here. In 1924 I had the honour of being, for one year, a member of the British Museum East Africa Expedition which was excavating for Dinosaur remains in Tanganyika Territory under the leadership of the late Mr. Cutler. Further on, reference is made to $m y$ " work in investigating stone-age remains in Uganda." Nairobi and Nakuru are towns in Kenya Colony, and it is regrettable that the archæological work in the two countries should be confused.

\section{Some Difficulties in Relativity.}

By Prof. S. Brodetsky, University of Leeds.

$\mathrm{T}$ HE special theory of relativity was formulated by Albert Einstein twenty-two years ago. The gencral theory with its application to universal gravitation was published eleven years ago. The relativistic viewpoint has become an accepted principle and instrument in physical science. Yet a complete understanding of the ideas underlying it is comparatively rare among laymen, and far from bcing universal even among men of science. This is natural, since the theory of relativity presupposes a break with preconceived notions, hallowed by unquestioning acceptance at the hands

No. 3011, Vor. 120] 